See discussions, stats, and author profiles for this publication at: https://www.researchgate.net/publication/313509419

\title{
Isomerization of Fatty Acids: A Cellular Barrier Mechanism in Nanotechnology?
}

Article in Journal of Nanoscience and Nanotechnology · January 2017

DOI: $10.1166 /$ jnn.2017.13791

CITATIONS

4 authors, including:

Rodolfo Gonzalez-Paz

High-Tech National Center (CeNAT), Costa Rica

29 PUBLICATIONS 154 CITATIONS

SEE PROFILE

José Roberto Vega-Baudri

National University of Costa Rica

222 PUBLICATIONS 619 CITATIONS

SEE PROFILE

Some of the authors of this publication are also working on these related projects:

CHITIN AND CHITOSAN FROM MARINE WASTES View project

Project

Costa Rican chemistry olympiads View project
371

Virginia Cadiz

Universitat Rovira i Virgili

199 PUBLICATIONS 4,824 CITATIONS

SEE PROFILE 


\title{
Isomerization of Fatty Acids A Cellular Barrier Mechanism in Nanotechnology?
}

\author{
Rodolfo González-Paz ${ }^{1, *}$, Virginia Cádiz², Riccardi Kiara ${ }^{1}$, and José Vega-Baudrit ${ }^{1,3}$ \\ ${ }^{1}$ National Nanotechnology Laboratory LANOTEC-CeNAT-CONARE, San José, Costa Rica \\ ${ }^{2}$ Department of Analytical Chemistry and Organic Chemistry, Universidad Rovira y Virgili, Campus Sescelades, \\ Marcel.lí Domingo s/n., 43007 Tarragona, Spain \\ ${ }^{3}$ Polymers Laboratory, Faculty of Chemistry, Universidad Nacional, POLIUNA, Heredia, Costa Rica
}

\begin{abstract}
This work is a kinetic study of the coupling reaction of 2-mercaptoethanol with methyl undecenoate and with methyl oleate through "click" chemistry. Reversibility and reactivity of each system were followed through Fourier Transform Infrared Spectroscopy and ATR conversion (FTIR-ATR) and Nuclear Magnetic Resonance Spectroscopy ( ${ }^{1} \mathrm{H}$ NMR). It was proved that the addition of thiol to the alkene may be reversible, that it depends on factors such as the structure of the alkene and the concentration of thiol or photoinitiator, but that it is mainly affected by the isomerization process in fatty acids and the reactivity of each configuration (cis or trans). It was concluded that under our "click" chemical experimental conditions, the cis form of methyl oleate is more reactive than the trans form. Finally, the plausibility of applying this process in nanotechnology is discussed as a cellular barrier mechanism to avoid internalization of toxic nanoparticles.
\end{abstract}

Keywords: Isomerization, Fatty Acids, Thiyl Radicals, Cellular Membrane, Nanotechnology.

\section{INTRODUCTION}

Nanotechnology has been globally declared as a high priority field of research not only in academia but also in politics, since it embraces myriad of potential applications in pharmaceutical, food and electronic industries. In 2009, the nanotechnology sector generated a total of US\$ 12 billion, and it is forecast a massive expansion in this area in the coming decades. Nevertheless, the increase in the amount of nanotechnology based products has been accompanied by permanent uncertainty which characterizes the evolution of scientific knowledge in this field, as well as the social trajectory of their technological applications. This situation inevitably hinders efforts to create regulations for the development and uses of this type of technology. ${ }^{1}$

Nanomaterials have the potential to revolutionize medicine because of their capacity to affect organs, tissues and even cells at molecular levels. One of the principal concerns related to human health risk is the possibility that nanoparticles may pass through the cellular membrane and interact with biomolecules inside the cell. However,

*Author to whom correspondence should be addressed. it is possible to take advantage of this feature in order to get rid of malign cells through delivery systems or other mechanism. Nevertheless, the behavior of nano sized materials is usually unpredictable as compared with their macro or even micro counterparts. This reason justifies the concern about unspecific internalization of nanomaterials which could cause serious damage to vital organs such as the brain. ${ }^{2}$

In previous work ${ }^{3}$ it has been observed that an isomerization process occurs during thiol-ene coupling in fatty acids with double internal bonds. Isomerization of unsaturated fatty acids catalyzed by thiyl radicals has been studied for several years, ${ }^{4-6}$ mainly because it may contribute to the conversion of the cis to the trans configuration of unsaturated phospholipids present in cellular membranes (Fig. 1). This isomerization generates important structural changes in these membranes, affecting their barrier properties, because the trans configuration may pack better and prevent passage of unwanted molecules through the cellular membrane.

This barrier mechanism could be used to prevent nanoparticles from passing through the cellular membrane (Fig. 1), but to do this it is necessary to understand this isomerization process, as well as the reactivity of cis and 


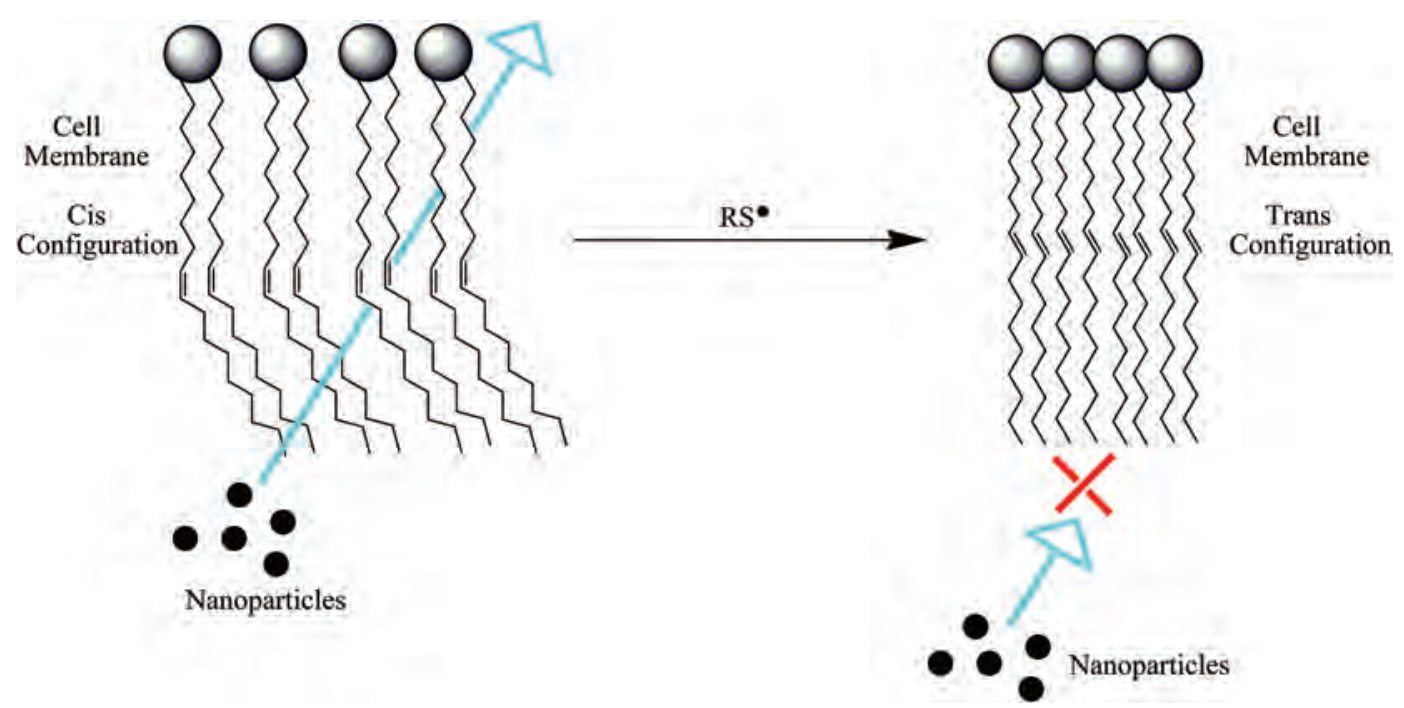

Figure 1. Cis-trans isomerization of unsaturated fatty acids present in phospholipids of cellular membranes in the presence of thiyl radicals (RS·) as a proposed mechanism of cell barrier against nanoparticles.

trans configurations when confronted by these radicals and the biological implications of causing this structural changes, since inducing the trans form without any control could cause cell death or relevant metabolic repercussions, a mechanism which is currently under study as an antitumor therapy. ${ }^{7}$ Therefore, this work is focuses on the isomerization process, as well as the reactivity of cis and trans configurations when confronted by thiyl radicals.

Lowe $^{8}$ has recently published a review of previous studies, ${ }^{4,9,10}$ in which he mentions that the low reactivity of double internal bonds with thiyl radicals is not only due to steric hindrances, but also to the fact that the isomerization process also reduces conversion speeds, because the cis and trans configurations have different thiol-alkene coupling speeds. ${ }^{11,12}$

There is still an ongoing debate on which of the two configurations (cis or trans) is more reactive. This work therefore presents a detailed study of isomerization reaction and conversion in the addition of 2-mercaptoethanol to ethyl oleate, using FTIR-ATR and NMR ${ }^{1} \mathrm{H}$ spectroscopy measurements. In addition, a comparative analysis on the addition of a thiyl radical to a double terminal bond and to an internal bond is carried out.

The reaction of the double bond of fatty acid with mercaptoethanol is a thiol-alkene coupling reaction, which has been used for many years to produce numerous materials. ${ }^{13}$ It is frequently used in coatings where UV light induces a crosslinking (photocuring) between unsaturated polymers and multifunctional thiol, showing the great advantage of not using heavy metal catalysts as curing agents. In addition, these are fast, simple, specific reactions which are tolerant of many functional groups, effective under soft conditions, compatible with oxygen and water, requiring neither anhydrous nor inert conditions. All these features make thiol-alkene coupling reactions highly sustainable and biocompatible, allowing them to be "click" reactions as defined by Sharpless ${ }^{14}$ in 2001. As a result, many researchers have recently synthesized new materials with applications in several areas such as nanotechnology using "click" thiol-ene coupling reactions. ${ }^{15-19}$

\section{MATERIALS AND METHODS}

The following chemical products were obtained from the mentioned sources: oleic acid (from Mallinckrodt), and 10-undecenoic acid (from Merquinsa) were used as received to synthesize methyl 10-undecenoate (MUD) and methyl oleate (MOL), following standard procedures. ${ }^{3}$ Lithium aluminum hydride $\left(\mathrm{LiAlH}_{4}\right)$ at $95 \%$ from Aldrich, 2,2-dimethoxy-2-phenylacetophenone (DMPA) at $99 \%$ from Aldrich, 2-mercaptoethanol at $99 \%$ from Aldrich.

\subsection{Thiol-Alkene Double-Bond Coupling Reaction}

To study the thiol-ene coupling reaction, 10-undecenoate methyl and methyl oleate were used as alkenes. 2-mercaptoethanol was always used as the thiol. In one of the systems, the 2,2-dimethoxy-2-phenylacetophenone (DMPA) was used as the photoinitiator in the free-radical reaction. The reactions were carried out using a UV $(4 \mathrm{~W})$ lamp with a $\lambda=365 \mathrm{~nm}$ wavelength and magnetic agitation at $250 \mathrm{rpm}$. The addition of thiol to alkene and the isomerization process was followed using FTIR-ATR absorption bands of the cis and trans configurations of the double bond, and through NMR ${ }^{1} \mathrm{H}$ using integration of the signals corresponding to the protons of the $\mathrm{C}=\mathrm{C}$ double bond. 


\subsection{Thin-Layer Chromatography}

Silica gel plates on Merck 60 F254 aluminum were used to distinguish the different components. A carbonizable compound developer $(0.5 \mathrm{ml}$ of anysaldhyde and $1 \mathrm{ml}$ of sulphuric acid in $50 \mathrm{ml}$ of ethanol) was used. Before use, the silica plates were first introduced into the developer solution and immediately taken out and heated at a temperature of approximately $200{ }^{\circ} \mathrm{C}$ until stains were seen. A mix of 9/1 ethylhexanol acetate was used as an eluent.

\subsection{Nuclear Magnetic Resonance (NMR) Spectroscopy}

The ${ }^{1} \mathrm{H}$ and ${ }^{13} \mathrm{C}$ NMR spectra were performed in a Varian Mercury Vx 400 spectrometer with Fourier Transforms, operating at $400 \mathrm{MHz}$ for ${ }^{1} \mathrm{H}$ and at $100 \mathrm{MHz}$ for ${ }^{13} \mathrm{C}$. The solvent used was deuterated chloroform $\left(\mathrm{CDCl}_{3}\right)$. The chemical shifts are indicated in ppm, using tetramethylsilane (TMS) as an internal standard.

\subsection{Fourier Transform Infrared Spectroscopy and ATR Conversion (FTIR-ATR)}

Infrared spectra were recorded in a FTIR-ATR JASCO 680 spectrophotometer. For the isomerization and kinetic studies of thiol-alkene coupling reactions, a UV (4 W) lamp $\lambda=365 \mathrm{~nm}$ was coupled to the spectrophotometer at a distance of $20 \mathrm{~cm}$ from the sample holder where the reaction took place.

\section{RESULTS AND DISCUSSION}

The production of a thiyl radical in thiol-alkene reactions may be thermically or photochemically induced, taking place through a free-radical reaction mechanism (Scheme 1), which was initially outlined in 1938 by Kharash et al., ${ }^{20}$ where once the thiyl radical is produced, it is added to the $\mathrm{C}-\mathrm{C}$ double bond, and later an $\mathrm{H}$ is detached from another thiol molecule to form the product; the last step is the slowest part of the reaction.

As previously mentioned, this work studies thiol-ene coupling in unsaturated fatty acids, the isomerization

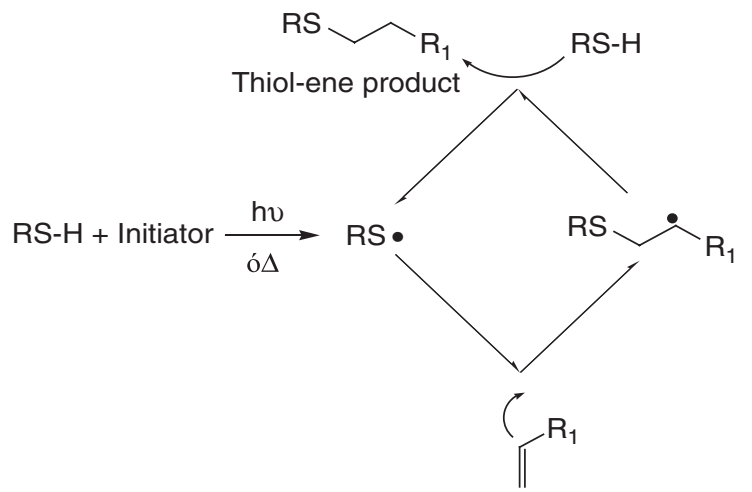

Scheme 1. Free-radical reaction mechanism for the thiol-alkene coupling reaction. process during this coupling, and the reactivity of the cis and trans configurations. It was determined that the thiolalkene addition may indeed be reversible, ${ }^{9}$ as described, and depends on several factors: the structures of the alkene and/or thiol, thiol concentration, solvents used, temperature, and the presence and concentration of a photoinitiator. There are few studies on the effect of the structures of the alkene and/or thiol on this reaction, and it is therefore extremely important to determine the optimal conditions for the reaction to be irreversible, i.e., without generating isomerization, so that thiol-alkene coupling takes place efficiently. ${ }^{8}$

Methyl undecenoate is a compound with a terminal $\mathrm{C}=\mathrm{C}$, which is obtained from esterification of 10 -undeceoic acid (the principal product of pyrolysis and hydrolysis of castor oil). ${ }^{21}$ Roper et al. ${ }^{11}$ showed that terminal double bonds quickly react with thiol, generating complete irreversible conversions, regardless of the length of the aliphatic chain, due to easy access by the thiyl radical $\left(\mathrm{RS}^{*}\right)$ to the double bond, since there are no steric hindrances. On the other hand, the intermediate radical formed (Fig. 2) does not have any type of interaction to stabilize this radical, which translates into the rapid detaching of an $\mathrm{H}$ from another thiol molecule to yield the product. For this reason, in terminal double bonds the slow step of thiol-alkene coupling reaction (detaching an $\mathrm{H}$ ) takes place quickly and the process is not reversible. Thiol-ene coupling systems have therefore been proposed in terminal double bonds without the use of photoinitiators, although this reaction mechanism has not been clearly defined. ${ }^{22,23}$

Taking the aforementioned points into account, this study found that the best reaction conditions for methyl undecenoate and 2-mercaptoethanol with a molar relationship of 1:1.8, respectively, were: room temperature, light at $\lambda=365 \mathrm{~nm}$, and without photoinitiator (DMPA). The reaction took place irreversibly with a very good yield (95\%) the total conversion of the double bonds occurred in only 40 minutes, and the final product showed a high level of purity. The ${ }^{1} \mathrm{H}$ and ${ }^{13} \mathrm{C}$ NMR spectra are presented below.

In the proton spectrum the triplet can be seen at $2.51 \mathrm{ppm}$ ( $k$ signal), which verifies the formation of the new $\mathrm{CH}_{2}-\mathrm{S}$ bond. In addition, both the integration of all the signals as well as their shifting and multiplicity correspond to the proposed thiol-ene coupling structure. Likewise, the ${ }^{13} \mathrm{C}$ NMR spectrum confirms the creation of the expected product, as can be seen in Figure 4 where all signals and their corresponding values can be observed.

The second thiol-ene coupling system studied corresponds to the reaction of methyl oleate (MOL) with

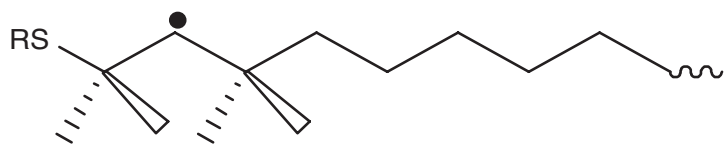

Figure 2. Radical intermediary formed in a terminal double bond during thiol-eno coupling. 


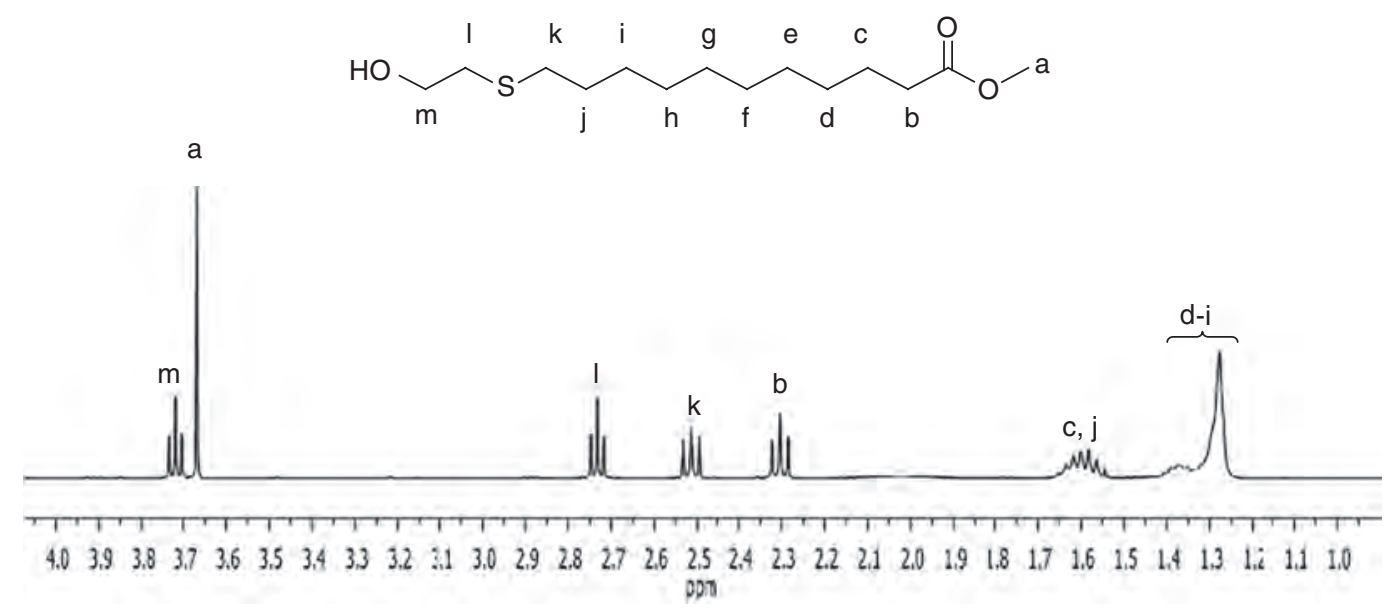

Figure 3. NMR of ${ }^{1} \mathrm{H}\left(400 \mathrm{MHz}, \mathrm{CDCl}_{3}\right)$ of 11-(2-hydroxyethyl)methyl undecenoate.

2-mercaptoethanol. In this case, the MOL shows an internal $\mathrm{C}=\mathrm{C}$ in the cis configuration in the natural state, which impedes the addition of the thiyl (RS*) radical even more due to steric hindrance; in addition, the steric strain resulting from the thiol coupling in the internal double bond has a dramatic effect on conversion speed, which allows time for the reaction to be reversible. In general, as the size of the substituent is increased on both sides of the double bond, the conversion speed decreases. ${ }^{11}$

Chatgilialoglu et al. $^{4}$ have carried out kinetic studies with MOL, changing the thiol concentration (2-mercaptoethanol) and using a photoinitiator, to determine the optimal conditions to achieve total conversion.
These authors determined that for thiol concentrations $>0.1 \mathrm{M}$ it is possible to obtain total conversion, while for thiol concentrations $<0.1 \mathrm{M}$ there is no conversion, and only double bond isomerization is observed (Scheme 2), because fragmentation of the intermediate radical $\left(\mathrm{A}^{*}\right)$ towards the initial cis configuration or towards the trans configuration takes place faster than the detaching of an $\mathrm{H}$ from another thiol molecule to yield the final product ( $\mathrm{kf}$ cis and $\mathrm{kf}$ trans $>\mathrm{kSH}$ ), as opposed to thiol concentrations $>0.1 \mathrm{M}$ where this fragmentation competes with the detaching of the $\mathrm{H}^{5}$

We proposed several formulations (F1-F5), varying the thiol and photoinitiator concentration (Fig. 5) to study the effect of increases in the photoinitiator and thiol

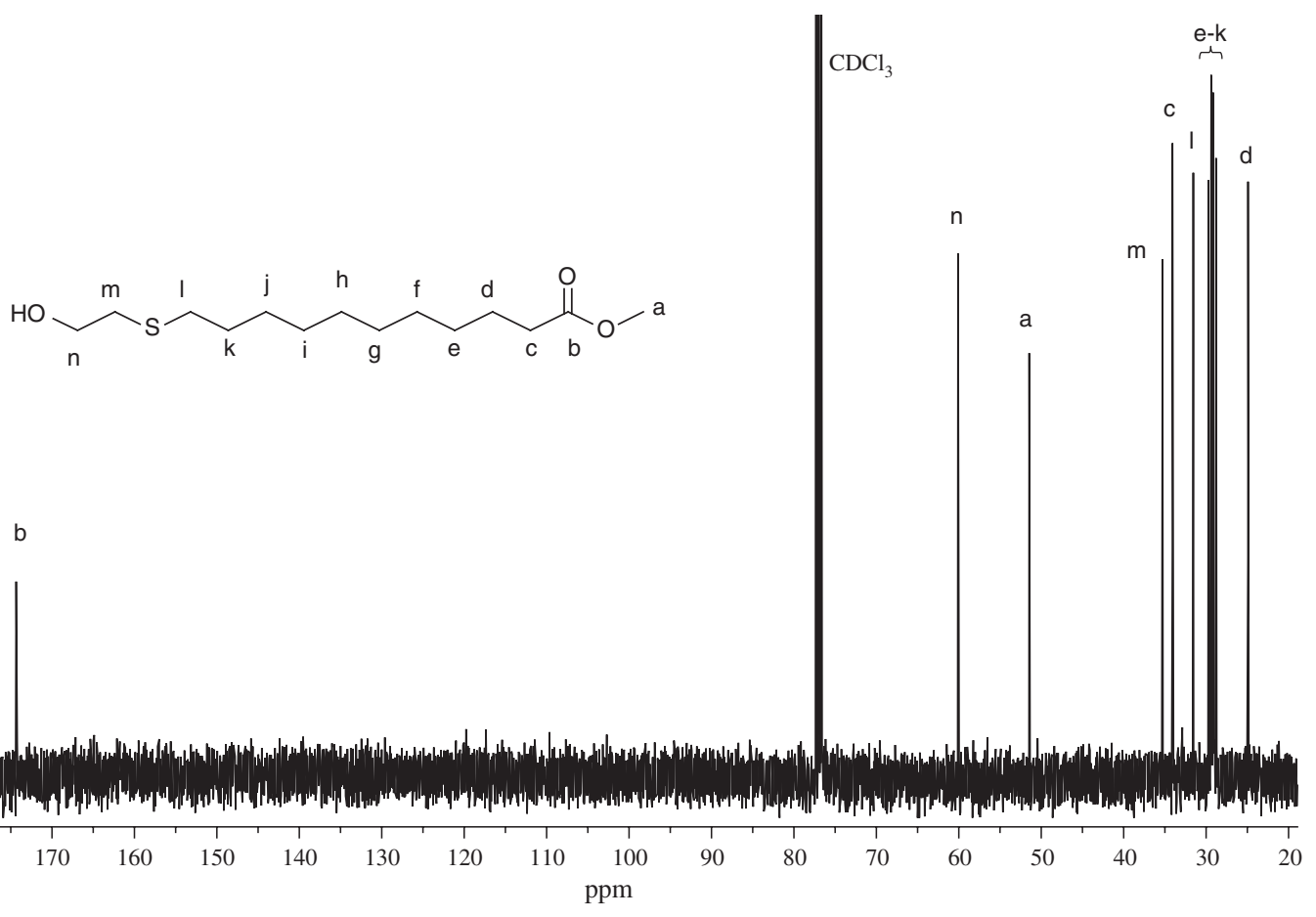

Figure 4. $\mathrm{NMR}$ of ${ }^{13} \mathrm{C}\left(100 \mathrm{MHz}, \mathrm{CDCl}_{3}\right)$ of 11-(2-hydroxyethyl)methyl undecenoate. 


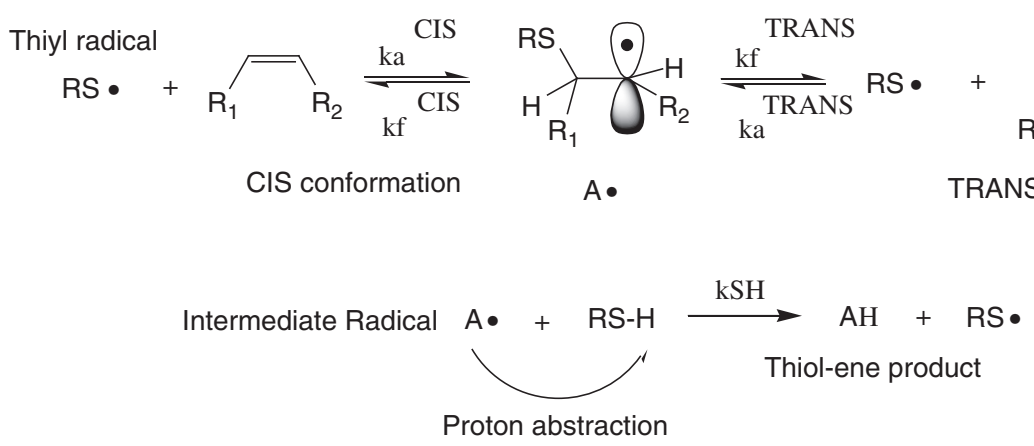

Scheme 2. Isomerization mechanism and kinetic of fatty acids catalyzed by thiyl radicals.

concentrations to achieve total conversion of the MOL double bond.

Figure 5 shows $\mathrm{C}=\mathrm{C}$ conversion through time; as can be seen, between F1 and the F2, where only the thiol concentration varies (an increase of $0.3 \mathrm{~mol}$ ), the conversion increases remarkably during the reaction process. After 3 hours $72 \%$ conversion was reached for F1, while for F2, $88 \%$ conversion was reached, although we can also see that conversion speed beginning at that point decreases markedly - at six hours the conversions reached were $77 \%$ and $90 \%$ respectively, and at 24 hours the conversion had not yet reached 100\% (F1: $87 \%$ and F2: 95\%). In F3 and F4 the amount of photoinitiator was increased compared to F2 (0.024 mol and 0.049 mol respectively) and $93 \%$ conversion was reached after 3 hours of reaction, but likewise, $100 \%$ conversion was not reached during the reaction. A little more thiol $(0.3 \mathrm{~mol})$ was added in F5 compared to $\mathrm{F} 4$, and $95 \%$ conversion was reached after only $1 \mathrm{~h}$, and after $6 \mathrm{~h}, 99 \%$ conversion was achieved. This last combination of factors (F5), which produced a total conversion of the $\mathrm{C}=\mathrm{C}$ of the MOL, made it possible to establish the ratio of $1.8 \mathrm{~mol}$ thiol $/ 1 \mathrm{~mol} \mathrm{C}=\mathrm{C}$ and $0.085 \mathrm{~mol} \mathrm{DMPA} / 1 \mathrm{~mol} \mathrm{C}=\mathrm{C}$ as the most appropriate method.

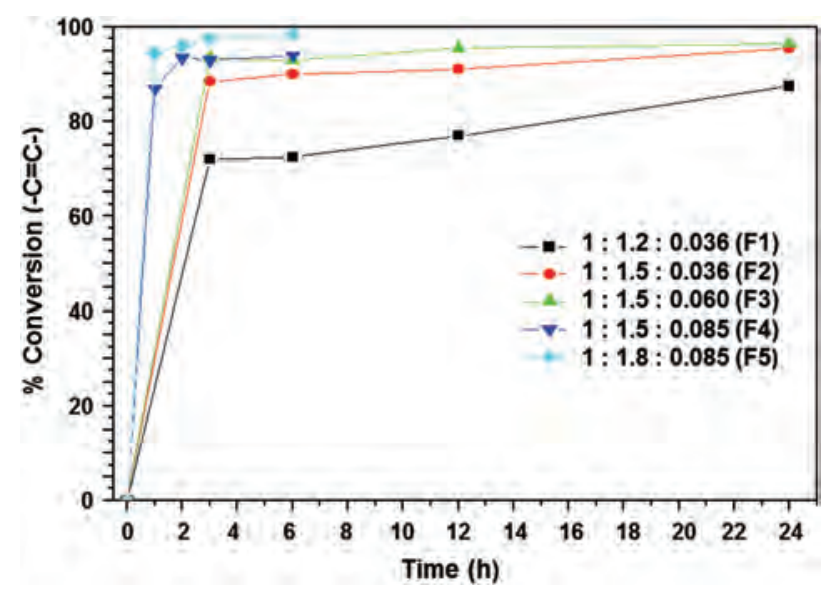

Figure 5. Conversion of the double bond according to time measured by ${ }^{1} \mathrm{H}$ NMR, according to the molar ratio of the reactants: methyl oleate:2-mercaptoethanol:DMPA.
This kinetic study of the thiol-ene coupling reaction demonstrated that the thiol concentration added initially to the formulation is indeed the principal factor that has an effect on the speed of the conversion of the internal double bond, rather than the initial concentration of the initiator (DMPA).

The ${ }^{1} \mathrm{H}$ and ${ }^{13} \mathrm{C}$ NMR spectra for the product obtained according to F5 are presented below.

Figure 6 corresponds to the ${ }^{1} \mathrm{H}$ NMR spectrum of the product obtained using F5, and as can be seen, the signal $h$ in the form of a quintuplet at $2.57 \mathrm{ppm}$ verifies the formation of a new CHS bond. Furthermore, both the integration of all the signals and their shifting and multiplicity correspond to the proposed structure. Likewise, the ${ }^{13} \mathrm{C}$ NMR spectrum confirms the creation of the product, as may be seen in Figure 7.

During the 1960s, Sivertz et al. ${ }^{24-26}$ and Walling and Helmreich ${ }^{9}$ determined that the speed constants for addition of thiyl radicals to the cis and trans configurations of some alkenes are different, as are the fragmentation speed constants of the intermediate radical formed in each conformation. Several years ago Chatgilialoglu et al. ${ }^{5}$ found that for methyl oleate, speeds of addition of the thiyl radical to the cis and trans forms have the same order of magnitude and are practically equal, while the fragmentation speed of the intermediate radical $A^{*}$ (Diagram 2) to yield a trans configuration is an order of magnitude greater $\left(\mathrm{kf}\right.$ TRANS $\left.=1.6 \times 10^{8} \mathrm{M}^{-1} \mathrm{~s}^{-1}\right)$ than that which yields the cis form $\left(\mathrm{kf} \mathrm{CIS}=1.7 \times 10^{7} \mathrm{M}^{-1} \mathrm{~s}^{-1}\right)$, so the fast fragmentation of the intermediate radical $\mathrm{A}^{*}$ in the trans isomer is attributed to the low activation barrier (kf TRANS $>>\mathrm{kf}$ CIS) for the formation of the trans isomer from the intermediate free-radical reaction $\mathrm{A}^{\text {: }}$.

On the other hand, Hoyle et al. ${ }^{11}$ studied reactivity of some monofunctional alkenes with an internal or terminal $\mathrm{C}=\mathrm{C}$ with a monofunctional thiol, 3-ethyl mercaptopropionate, and their results demonstrated that the trans configuration in internal double bonds shows reduced reactivity with thiol, and a lower total conversion in internal double bonds than with a terminal $\mathrm{C}=\mathrm{C}$, which they attribute to the resulting steric strain due to the 1-3 interactions of the intermediate free-radical reaction (Fig. 8). They 


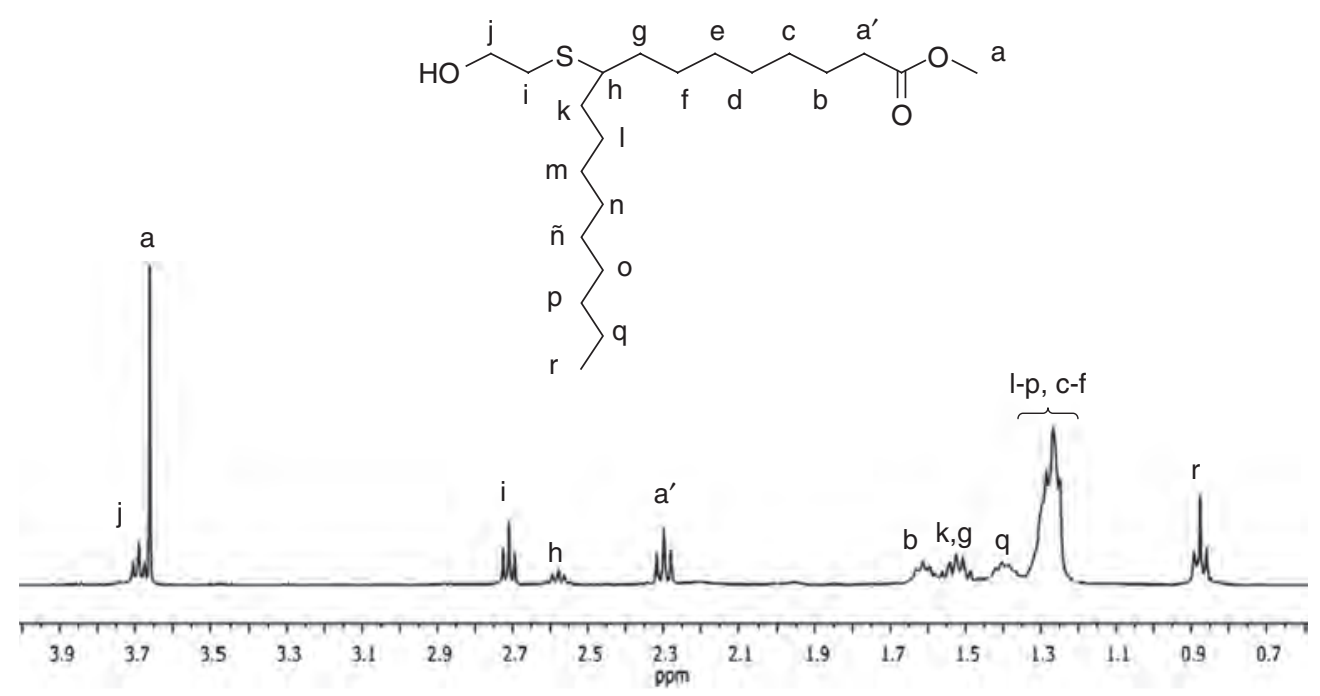

Figure 6. $\mathrm{NMR}$ of ${ }^{1} \mathrm{H}\left(400 \mathrm{MHz}, \mathrm{CDCl}_{3}\right)$ of 9-(2-hydroxyethyl)methyl octadecanoate.

confirm that reactivity and conversion of the $\mathrm{C}=\mathrm{C}$ trans decrease when the substituents of the $\mathrm{C}=\mathrm{C}$ are larger, reaching a minimum when the size of the substituent is equal or greater than that of a propyl, and that the cis $\mathrm{C}=\mathrm{C}$ react quickly with thiol, but experience rapid isomerization generating the trans isomer, which then reacts at reduced speed with the thiol.

Samuelsson et al. ${ }^{12}$ studied reactivities and reaction speeds of thiol-ene coupling of methyl oleate and of methyl linoleate with two different thiols, two trimercap$\tan$ derivatives. They observed that the structure of both the thiols and of the $\mathrm{C}=\mathrm{C}$ have an important effect on the reaction of the thiol-ene addition. They studied the reversibility of the thiol-ene addition by measuring FTIR and NMR, and found greater isomerization speeds in oleate systems, as compared to those of linoleate, which they attribute to more limited rotation of the $\mathrm{C}-\mathrm{C}$ bond (after the addition to the $\mathrm{C}=\mathrm{C}$ ) in the linoleate. They also observed that cis unsaturation in the methyl oleate isomerizes much faster, which has important implications for thiols' total addition speed because according to their results the trans isomer is more reactive than the cis isomer. In any case, total $\mathrm{C}=\mathrm{C}$ conversion reached for all the systems were around $70 \%$.

The current investigation carried out a detailed study of isomerization and conversion reaction in the addition

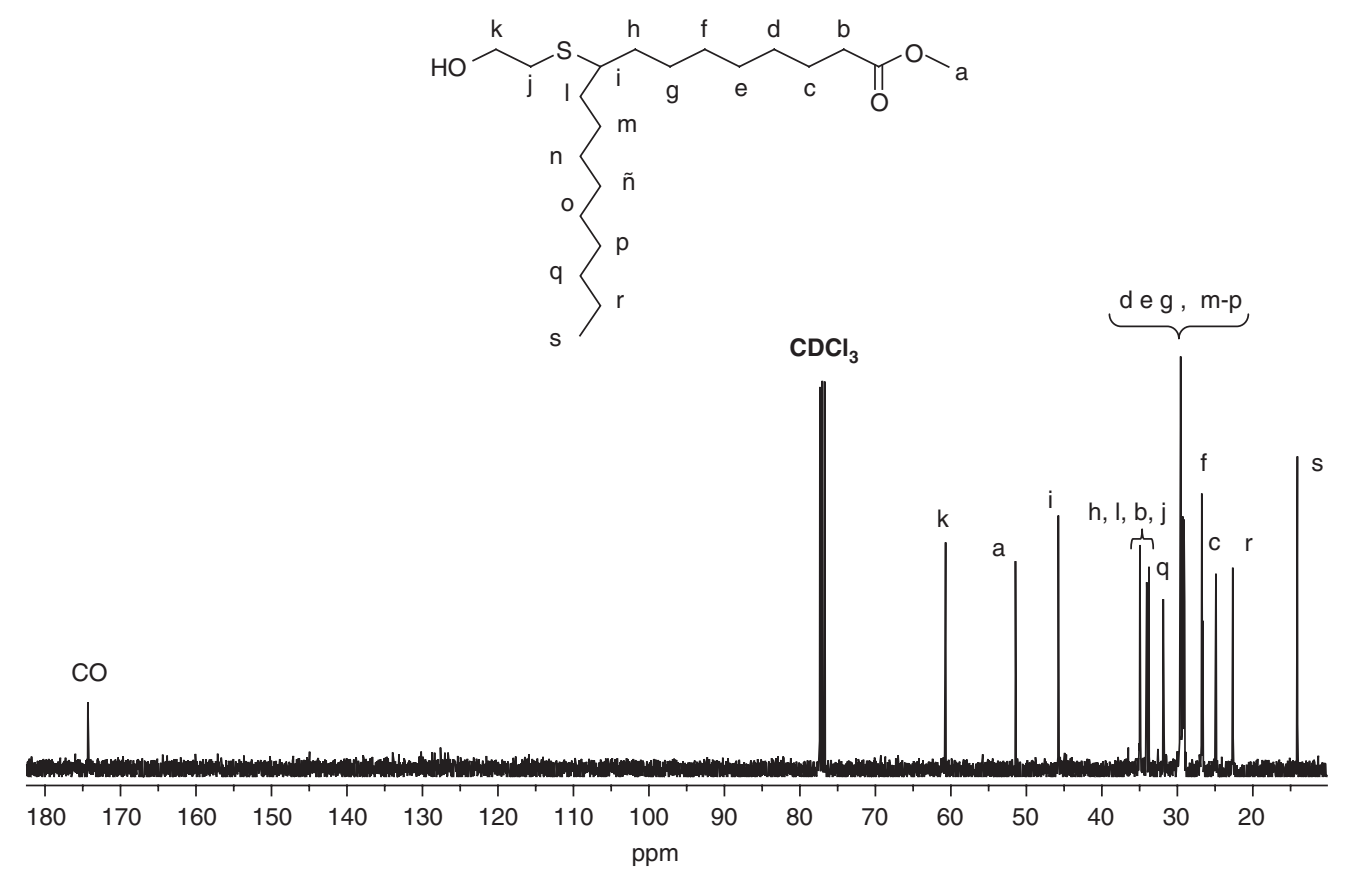

Figure 7. $\mathrm{NMR}$ of ${ }^{13} \mathrm{C}(100 \mathrm{MHz}, \mathrm{CDCl} 3)$ of 9-(2-hydroxyethyl)methyl octadecanoate. 


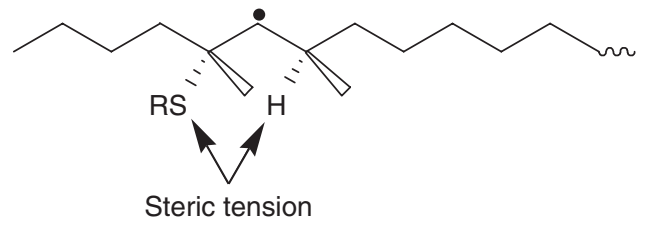

Figure 8. Intermediate radical formed in the internal double bond trans configuration during a thiol-alkene coupling.

of 2-mercaptoethanol to methyl oleate using FTIR-ATR and ${ }^{1} \mathrm{H}$ NMR spectroscopy measurements, reaching conversion rates of $100 \%$. In FTIR-ATR the bands selected were $3005 \mathrm{~cm}^{-1}$ for the cis configuration and $968 \mathrm{~cm}^{-1}$ for the trans configuration, and in proton NMR a double bond signal at $5.3 \mathrm{ppm}$ was used which made it possible to follow the conversion of the reaction, measuring its decrease until it disappeared.

The results obtained are presented in Figures 9-12. Figures 9 and 10 show an extension of the absorbance bands for the cis configuration $\left(3005 \mathrm{~cm}^{-1}\right)$ and for the trans configuration $\left(968 \mathrm{~cm}^{-1}\right)$, and their evolution at different reaction times. As can be seen, at the beginning of the reaction only the cis configuration exists, whose band disappears entirely after $1 \mathrm{~h}$, while the band of the trans isomer is not seen initially, becoming visible after $2 \mathrm{~min}$, reaching a maximum absorbance level at $15 \mathrm{~min}$, and totally disappearing at $3 \mathrm{~h}$.

This isomerization and conversion process was proved through ${ }^{1} \mathrm{H}$ NMR (Fig. 11) where at $0 \mathrm{~min}$ at $5.33 \mathrm{ppm}$ the signal for olefinic protons is observed in the $100 \%$ cis configuration, and after $5 \mathrm{~min}$ a new signal appears at $5.36 \mathrm{ppm}$ which corresponds to olefinic protons of the trans isomer. Then at $60 \mathrm{~min}$ the signal at $5.33 \mathrm{ppm}$ (cis) almost disappears, while the signal of the trans configuration at 5.36 totally disappears after $3 \mathrm{~h}$.

These results can be seen in a more comparative form in Figure 12, where the absorbance of each configuration

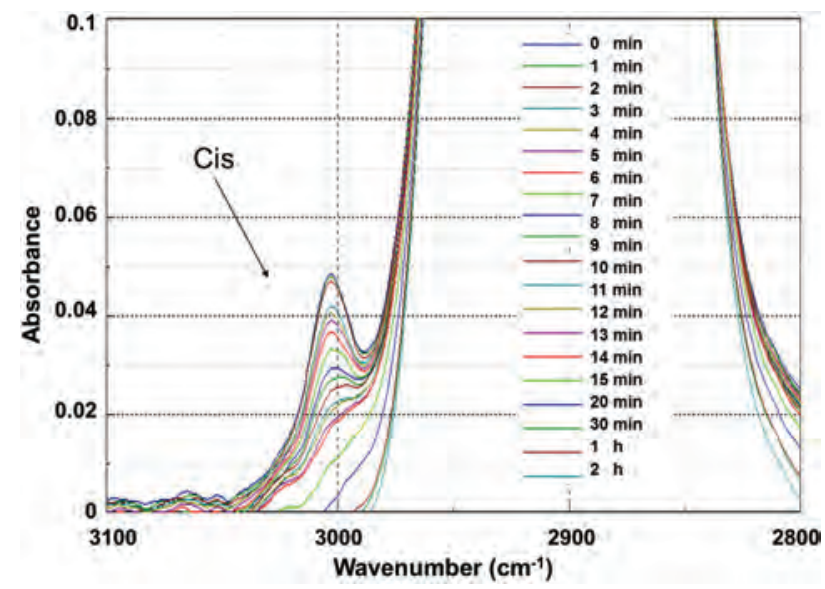

Figure 9. Isomerization followed by FTIR-ATR of the methyl oleate during coupling reaction with 2-mercaptoethanol, cis configuration $\left(3005 \mathrm{~cm}^{-1}\right)$.
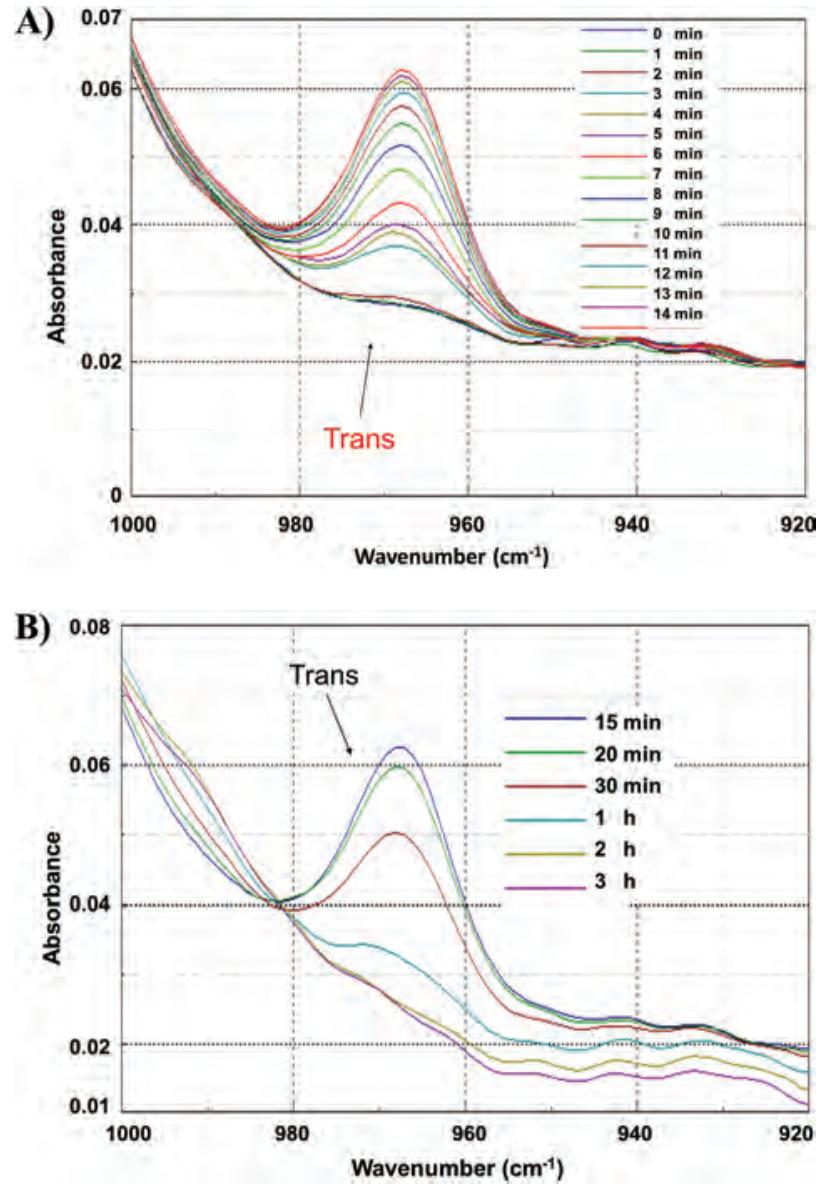

Figure 10. Isomerization followed by FTIR-ATR of the methyl oleate during coupling reaction with 2-mercaptoethanol trans configuration $\left(968 \mathrm{~cm}^{-1}\right)$ : (A) $t=(0-14) \mathrm{min}$ and (B) $t=15 \mathrm{~min}-3 \mathrm{~h}$.

was normalized and the conversion of the double bond through ${ }^{1} \mathrm{H}$ NMR was quantified. Absorbances were normalized using the band of asymmetric deformation of the $\mathrm{CH}_{3}$ at $1463 \mathrm{~cm}^{-1}$ as a reference, which remained constant throughout the process, and the conversion of the double bond through ${ }^{1} \mathrm{H}$ NMR was quantified using the triplet at $0.9 \mathrm{ppm}$ corresponding to $\mathrm{CH}_{3}$ as a reference signal.

The results stemming from the kinetic study of the 2-mercaptoethanol-to-methyl oleate coupling reaction demonstrate that there is indeed an isomerization process and that it is faster than total conversion of the double bond; the cis configuration of the methyl oleate reacts generating greater conversion rates in less time than the trans configuration. At $10 \mathrm{~min} 42 \%$ conversion was achieved, and during this time only the cis form reacted, since as can be seen (Fig. 12) the trans configuration starts to reduce its relative absorbance (concentration) at $15 \mathrm{~min}$. After $1 \mathrm{~h}$, the conversion rate was $72 \%$; during this time the cis configuration disappears, leaving only the trans configuration which takes 2 more hours to reach $100 \%$ conversion. 


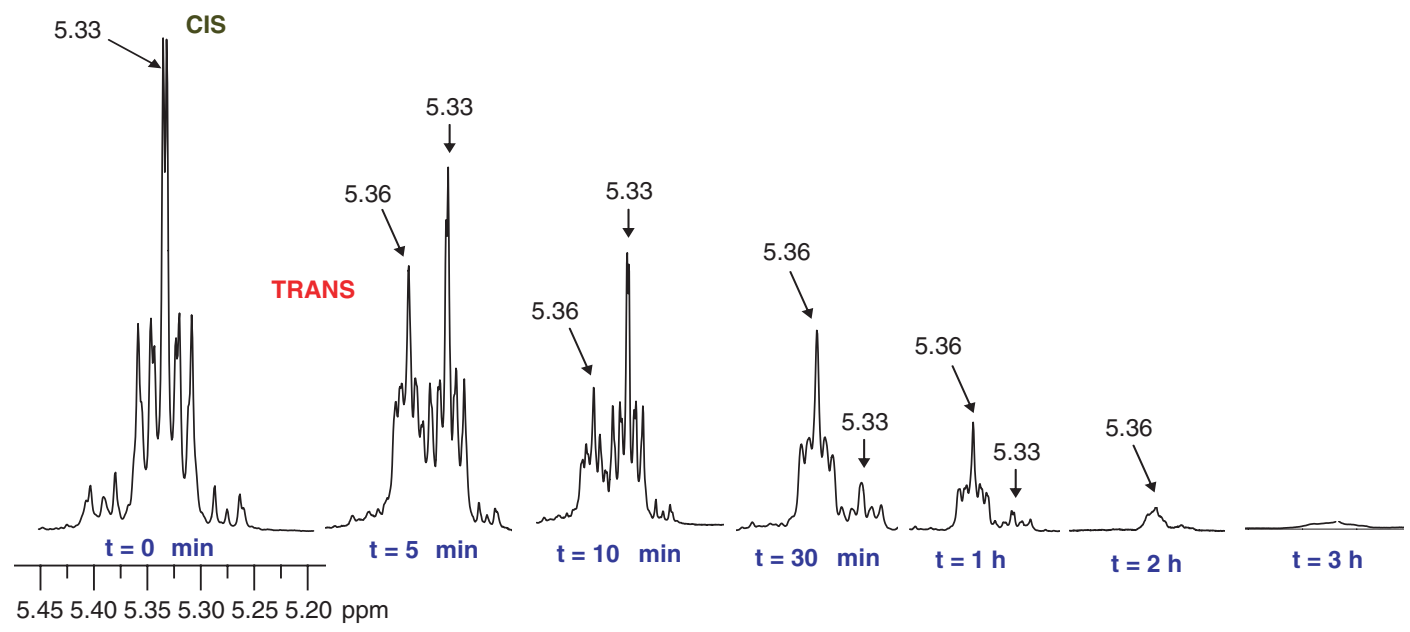

Figure 11. Extension of the 5.45-5.20 ppm zone of the ${ }^{1} \mathrm{H}$ NMR spectra during the kinetic study of the addition of the 2-mercaptoethanol to the methyl oleate.

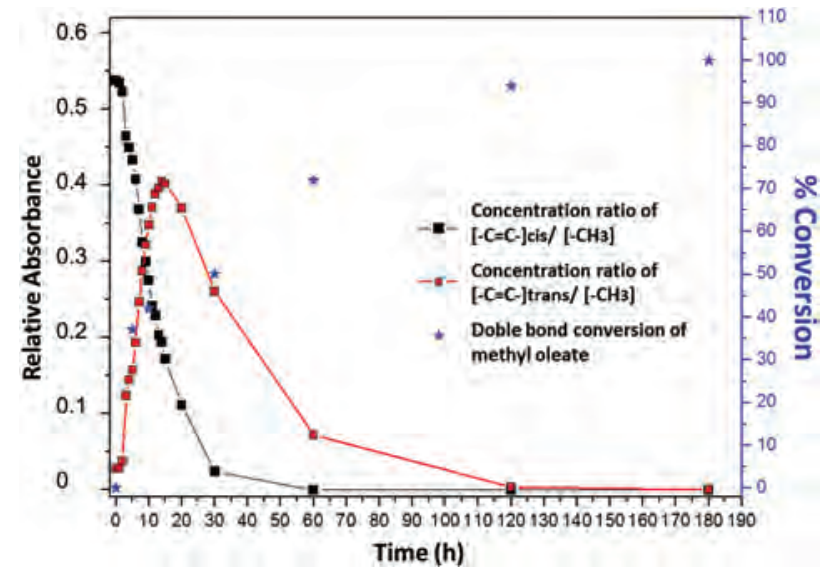

Figure 12. Relative absorbance measured through FTIR-ATR and double bond conversion of the methyl oleate measured through ${ }^{1} \mathrm{H}$ NMR during the kinetic study of the addition of the 2-mercaptoethanol.

\section{CONCLUSION}

This kinetic study on the reaction of the coupling of 2-mercaptoethanol to methyl undecenoate and to methyl oleate followed using FTIR-ATR and ${ }^{1} \mathrm{H}$ NMR demonstrates that addition of the thiyl radical to the terminal double bond indeed occurs in less time than that needed in the case of the internal double bond, and additionally that it is irreversible. On the other hand, it was shown that during the coupling reaction of 2-mercaptoethanol to methyl oleate an isomerization process takes place which is faster than total conversion of the double bond. It is clear that the cis configuration of the methyl oleate reacts yielding greater conversions more quickly than in the case of the trans configuration. For these reasons it may be concluded that under our "click" chemical experimental conditions, the cis form of methyl oleate is more reactive than the trans form.

These results and conformational analyses carried out using FTIR-ATR and ${ }^{1} \mathrm{H}$ NMR help to better understand the isomerization process in fatty acids, as well as the reactivity of the different configurations with thiyl radicals. This information could be highly useful in nanotechnology, to promote a barrier mechanism for preventing unwanted nanoparticles from passing through phospholipids of the cellular membrane when a configurational change is made that allows for better macromolecular packing of the membrane's physical structure. For instance, when surfaces of nanomaterials are functionalized with molecules that can generate thiyl radicals in the physiological medium near cellular membranes, these cellular barrier mechanisms could be modulated. Recently ${ }^{7}$ it has become possible to generate thiyl radicals in liposomes as biomimetic models of cellular membranes, using mercaptoethanol in the presence of belomicyn; this compound is capable of generating membrane isomerization towards the trans configuration and modulate different percentages of this configuration depending on thiol concentration. Finally, further investigations are needed in order to prove the cellular barrier mechanism of the studied systems and their potential use in nanotechnology.

\section{References and Notes}

1. S. Arnaldi and A. Muratorio, Nanoethics 7, 173 (2013).

2. W. L. Robison, Nanoethics 5, 1 (2011).

3. R. J. Gonzalez-Paz, C. Lluch, G. Lligadas, J. C. Ronda, M. Galia, and V. Cadiz, J. Polym. Sci.: Part A: Polym. Chem. 49, 2407 (2011).

4. C. Chatgilialoglu, A. Altieri, and H. Fischer, J. Am. Chem. Soc. 124, 12816 (2002).

5. C. Chatgilialoglu, A. Samadi, M. Guerra, and H. Fischer, Chem. Phys. Chem. 6, 286 (2005).

6. C. Chatgilialoglu, C. Ferreri, M. Ballestri, Q. Mulazzani, and L. Landi, J. Am. Chem. Soc. 122, 4593 (2000).

7. A. Cort, T. Ozben, A. Sansone, S. Barata-Vallejo, C. Chatgilialoglu, and C. Ferreri, Org. Biomol. Chem. 13, 1100 (2015).

8. A. B. Lowe, Polym. Chem. 1, 17 (2010).

9. C. Walling and W. Helmreich, J. Am. Chem. Soc. 81, 1144 (1959).

10. C. Ferrer, A. Samadi, F. Sassatelli, L. Landi, and C. Chatgilialoglu, J. Am. Chem. Soc. 126, 1063 (2004). 
11. T. M. Roper, C. A. Guymon, E. S. Jonsson, and C. E. Hoyle, J. Polym. Sci.: Part A: Polym. Chem. 42, 6283 (2004).

12. J. Samuelsson, M. Jonsson, T. Brinck, and M. Johansson, J. Polym. Sci.: Part A: Polym. Chem. 42, 6346 (2004).

13. C. Morgan, F. Magnotta, and A. Ketley, J. Polym. Sci. Polymer. Chem. Ed. 15, 627 (1977).

14. H. C. Kolb, M. G. Finn, and K. B. Sharpless, Angew. Chem. Int. Ed. Engl. 40, 2004 (2001).

15. M. W. Jones, G. Mantovani, S. M. Ryan, X. Wang, D. J. Brayden, and D. M. Haddleton, Chem. Commun. (Camb.) 35, 5272 (2009).

16. A. Dondoni, Angew. Chem. Int. Ed. 47, 8995 (2008).

17. M. Black and J. W. Rawlins, Eur. Polym. J. 45, 1433 (2009).

18. Q. Li, H. Zhou, and C. E. Hoyle, Polymer 50, 2237 (2009).
19. A. Lombana, Z. Raja, S. Casale, C. M. Pradier, T. Foulon, A. Ladram, and V. Humblot, J. Pept. Sci. 20, 563 (2014).

20. M. S. Kharasch, J. Read, and F. R. Mayo, Chem. Ind. 57, 752 (1938)

21. U. Bierman, W. Friedt, S. Lang, W. Lühs, G. Machmüller, J. O. Metzger, M. Rüsch Gen Klaas, H. J. Schäfer, and M. P. Schneiderusch, Angew. Chem. Int. Ed. 39, 2206 (2000).

22. N. B. Cramer, S. K. Reddy, M. Cole, C. Hoyle, and C. N. Bowman, J. Polym. Sci.: Part A: Polym. Chem. 42, 5817 (2004).

23. N. B. Cramer, J. P. Scott, and C. N. Bowman, Macromolecules 35, 5361 (2002).

24. R. H. Pallen and C. Sivertz, Can. J. Chem. 35, 723 (1957).

25. D. M. Graham, R. L. Mieville, and C. Sivertz, Can. J. Chem. 42, 2239 (1964).

26. D. M. Graham, R. L. Mieville, R. H. Pallen, and C. Sivertz, Can. J. Chem. 42, 2250 (1964).

Received: 31 May 2016. Accepted: 24 June 2016. 